to decrease further, $p=0.007$. No significant changes were observed in the placebo arm over time.

Conclusion: TNF inhibition improves arthritis-related brain activity in the subgroup of RA patients with high baseline BOLD activity in the fMRI.

References:

[1] Hess, A et al. PNAS (2011).

[2] Rech, J. et al. Arthritis \& Rheumatism (2013).

Acknowledgments: The study was supported by an unrestricted grant of UCB Biopharma SPRL Brussels, Belgium

Disclosure of Interests: Jürgen Rech Consultant of: BMS, Celgene, Novartis, Roche, Chugai, Speakers bureau: AbbVie, Biogen, BMS, Celgene, MSD, Novartis, Roche, Chugai, Pfizer, Lilly, Koray Tascilar: None declared, Hannah Schenker: None declared, Melanie Hagen: None declared, Marina Sergeeva: None declared, Mageshwar Selvakumar: None declared, Laura Konerth: None declared, Jutta Prade: None declared, Sandra Strobelt: None declared, Verena Schönau: None declared, Larissa Valor: None declared, Axel Hueber Grant/ research support from: Novartis, Lilly, Pfizer, EIT Health, EU-IMI, DFG, Universität Erlangen (EFI), Consultant of: Abbvie, BMS, Celgene, Gilead, GSK, Lilly, Novartis, Speakers bureau: GSK, Lilly, Novartis, David Simon Grant/ research support from: Else Kröner-Memorial Scholarship, Novartis, Consultant of: Novartis, Lilly, Arnd Kleyer Consultant of: Lilly, Gilead, Novartis, Abbvie, Speakers bureau: Novartis, Lilly, Frank Behrens Grant/research support from: Abbvie, Pfizer, Roche, Chugai, Janssen, Consultant of: Abbvie, Pfizer, Roche, Chugai, UCB, BMS, Celgene, MSD, Novartis, Biotest, Janssen, Genzyme, Lilly; Boehringer; Sandoz, Speakers bureau: Abbvie, Pfizer, Roche, Chugai, UCB, BMS, Celgene, MSD, Novartis, Biotest, Janssen, Genzyme, Lilly; Boehringer; Sandoz, Christoph Baerwald Consultant of: CGB received speaker or consulting fees from AbbVie, Paid instructor for: CGB received speaker or consulting fees from AbbVie, Speakers bureau: CGB received speaker or consulting fees from AbbVie, Stephanie Finzel: None declared, Reinhard Voll: None declared, Eugen Feist Consultant of: Novartis, Roche, Sobi, Lilly, Pfizer, Abbvie, BMS, MSD, Sanofi, Speakers bureau: Novartis, Roche, Sobi, Lilly, Pfizer, Abbvie, BMS, MSD, Sanofi, José Antonio P. da Silva Grant/research support from: Pfizer, Abbvie, Consultant of: Pfizer, AbbVie, Roche, Lilly, Novartis, Arnd Doerfler: None declared, Nemanja Damjanov Grant/research support from: from AbbVie, Pfizer, and Roche, Consultant of: AbbVie, Gedeon Richter, Merck, Novartis, Pfizer, and Roche, Speakers bureau: AbbVie, Gedeon Richter, Merck, Novartis, Pfizer, and Roche, Andreas Hess: None declared, Georg Schett Speakers bureau: AbbVie, BMS, Celgene, Janssen, Eli Lilly, Novartis, Roche and UCB DOI: 10.1136/annrheumdis-2020-eular.5249

\section{OP0118 DECIPHERING THE ANTI-PROTEIN-ARGININE DEIMINASE (PAD) RESPONSE IDENTIFIES PAD1 AND PAD6 AS NOVEL AUTOANTIGENS IN RHEUMATOID ARTHRITIS}

L. Martinez-Prat ${ }^{1}$, M. A. Aure ${ }^{2}$, C. Bentow ${ }^{2}$, D. Lucia², M. Lopez-Hoyos ${ }^{3}$, M. Mahler ${ }^{2} .{ }^{1}$ Inova Diagnostics, Research and Development, Barcelona, Spain; ${ }^{2}$ Inova Diagnostics, Inc., Research and Development, San Diego, United States of America; ${ }^{3}$ Marqués de Valdecilla University Hospital, Immunology, Santander, Spain

Background: Protein-arginine deiminase (PAD) 4 enzymes play a central role in the pathogenesis of rheumatoid arthritis (RA) and represents an antigenic target. Among the five known family members (PAD1, PAD2, PAD3, PAD4 and PAD6), only PAD2, PAD3 and PAD4 have been described to have autoantigenic properties. Furtheremore, very little is known on the the isotype usage of these autoantibodies. Understanding the molecular basis of the anti-PAD antibody reponse has the potential to open novel approaches for precision medicine in RA.

Objectives: The objectives of this study were to screen for the presence of antibodies to the five PAD family members and to evaluate the isotype usage of the anti-PAD4 response in RA.

Methods: First, we developed a panel for the detection of anti-PAD IgG based on a particle-based multi-analyte technology (PMAT), that utilized paramagnetic particles coupled with the different human recombinant PAD proteins (PAD1, PAD2, PAD3, PAD4 and PAD6) and anti-human IgG conjugate. This panel was used to test sera from RA patients $(n=33)$ and non-RA controls $(n=36)$. The controls were comprised of apparently healthy individuals $(n=10)$, and patients with infectious diseases $(n=10)$, systemic lupus erythematosus $(n=7)$, systemic sclerosis $(n=9)$ and Sjogren's syndrome $(n=1)$. Next, the PAD4-coupled beads were tested with anti-human $\lg \mathrm{M}$, IgA and IgG conjugates on an extended cohort of RA patients $(n=62)$ and the same non-RA controls.

Results: All five anti-PAD IgG (Figure 1) demonstrated the ability to discriminate between RA patients and controls. At greater than $90 \%$ specificity, antiPAD4 lgG, followed by anti-PAD3 IgG, showed the best diagnostic performance. Significantly higher levels of the five antibodies were observed in RA vs. controls ( $p$-values of $0.0041,<0.0001,0.0014,0.0039$, and 0.0140 for anti-PAD1, 2, 3, 4 and 6 , respectively). Significant correlation was observed between all the antibodies, with the highest between anti-PAD1 and anti-PAD4 (Spearman's $r h o=0.87, p<0.0001$ ) and the lowest between anti-PAD4 and anti-PAD2 (Spearman's $r h o=0.38, p=0.0015$ ) and anti-PAD4 and anti-PAD6 (Spearman's $r h o=0.38$, $p=0.0011$ ). While principal component analysis (PCA) (Figure 2) showed an association between all anti-PAD antibodies, there was further discrimination that displayed closer association between anti-PAD1, 3 and 4 on one hand, and between anti-PAD2 and 6. For the extended testing of anti-PAD4 with IgG, IgA and IgM, all three isotypes were identified in the sera of RA patients. Higher levels of the three isotypes were observed in RA patients with erosive disease when compared with the patients without erosion, but this association was only significant for anti-PAD4 IgA $(p=0.0086)$.

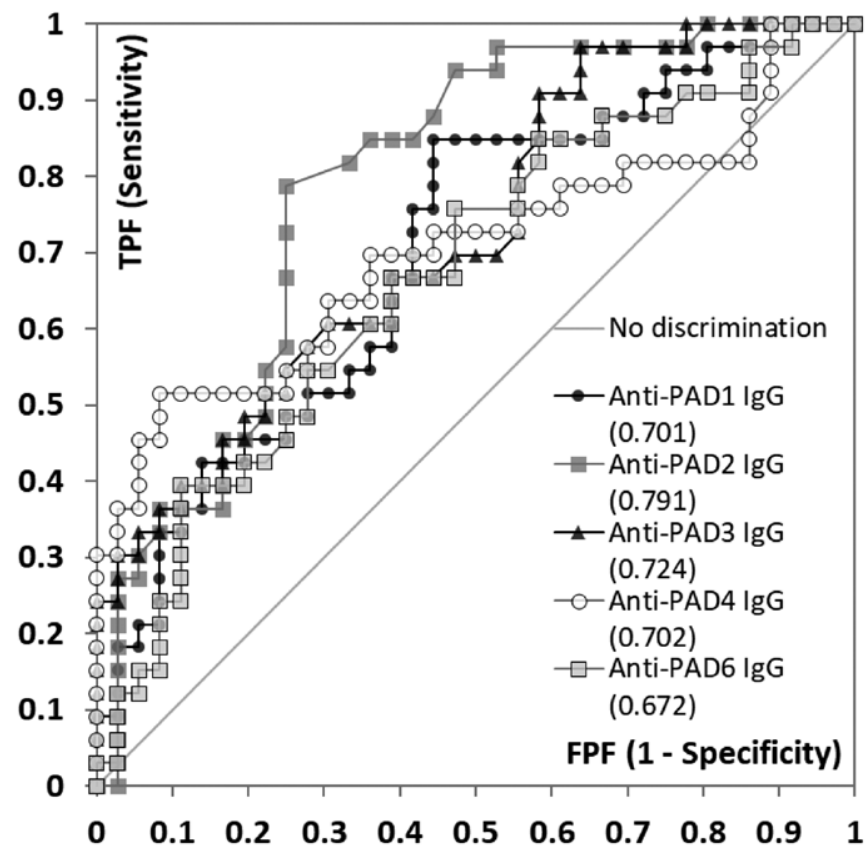

Figure 1. Receiver operating characteristics $(R O C)$ analysis of the discrimination between rheumatoid arthritis (RA) and controls of IgG to protein-arginine deiminase (PAD) 1, PAD2 PAD3, PAD4 and PAD6. The area under the curve (AUC) values are shown in brackets for each biomarker.Abbreviations: TPF: true positive fraction; FPF: false positive fraction

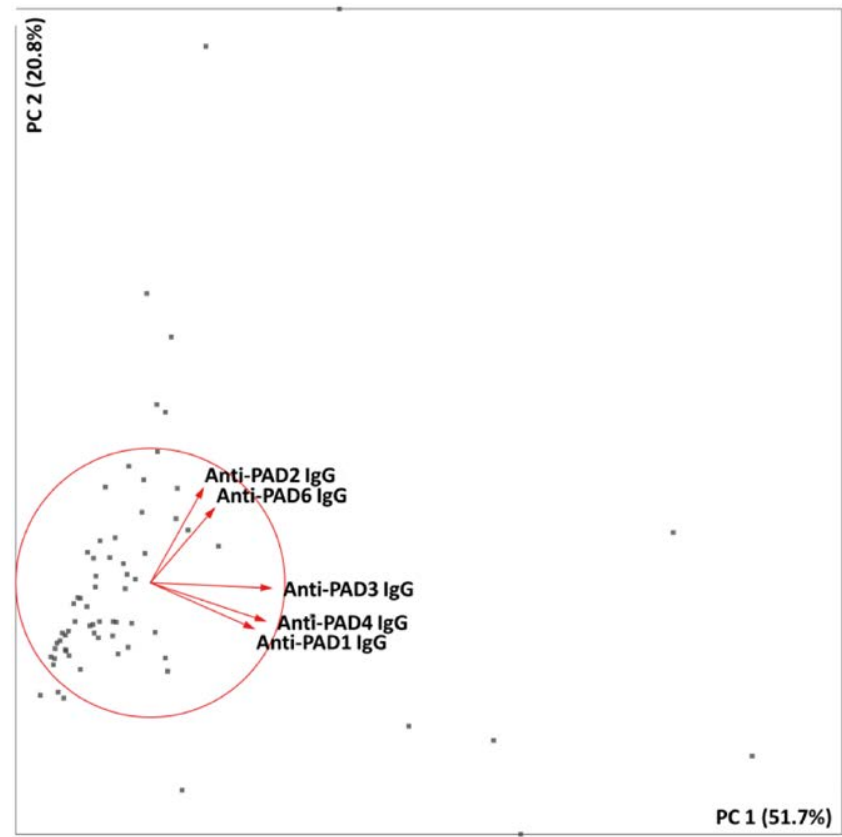

Figure 2. Two dimensional principal component analysis (PCA) plot of the anti-PAD levels in RA patients $(n=33)$ and controls $(n=36)$. Anti-PAD1, 3 and 4 have the main contribution to PC1, which explains $51.7 \%$ of the variance, and anti-PAD2 and 6 to PC2, that represents $20.8 \%$ of it.Abbreviations: PC: principal component 
Conclusion: Our study is the first to describe PAD1 and PAD6 as novel antigenic targets in RA and to demostrate that the anti-PAD4 B-cell immune response uses all three isotypes (IgG, $\lg A$ and $\lg M)$. The strong and significant association between anti-PAD4 IgA and joint erosion is of particular clinical relevance.

Disclosure of Interests: Laura Martinez-Prat Employee of: I am an employee of Inova Diagnostics, an in vitro diagnostics company., Mary Ann Aure Employee of: I am an employee of Inova Diagnostics, an in vitro diagnostics company., Chelsea Bentow Employee of: I am an employee of Inova Diagnostics, an in vitro diagnostics company., David Lucia Employee of: I am an employee of Inova Diagnostics, an in vitro diagnostics company., Marcos Lopez-Hoyos Consultant of: Inova Diagnostics, an in vitro diagnostics company., Michael Mahler Employee of: I am an employee of Inova Diagnostics, an in vitro diagnostics company.

DOI: 10.1136/annrheumdis-2020-eular.2853

\section{Cardiovascular disease and malignancies in RA}

\section{OP0119 NOT ALL THE SAME? REACHING REMISSION REDUCES THE RISK OF CVD IN PATIENTS WITH RA, BUT PATIENTS ON BIOLOGICS MAY BE BETTER PROTECTED}

I. J. Berg ${ }^{1}$, S. Lillegraven ${ }^{1}$, E. Kristianslund ${ }^{1}$, T. K. Kvien' ${ }^{1}$, S. Aarrestad Provan ${ }^{1}$. ${ }^{1}$ Diakonhiemmet Hospital, Rheumatology, Oslo, Norway

Background: Disease activity is a risk factor for the development of cardiovascular disease (CVD) in patients with rheumatoid arthritis (RA). Remission is the preferred treatment target in RA, and may be achieved by treatment with both conventional synthetic DMARDS (csDMARDs) and biologic DMARDS (bDMARDs).

Objectives: To compare the risk of CVD in patients reaching RA disease remission vs. non-remission by 6 months. Additionally; to compare the risk of CVD in RA patients reaching remission on bDMARDs vs. csDMARDs

Methods: The NOR-DMARD is a multi-centre prospective observational study that was established in 2000. Until 2012, patients who started on any DMARD were included, while only patients starting bDMARDSs were included after 2012. Disease activity and markers of inflammation (Erythrocyte Sedimentation Rate (ESR) and C-reactive protein (CRP $\mathrm{mg} / \mathrm{L}$ ) were measured at regular intervals. In these analyses we used data from baseline, 3-month and 6-month visits in patients with clinical RA included in the study from 2009. Patients with prior CVD were excluded from the study. Remission was assessed according to several criteria, and should be attained by the 6-month visit.

NOR-DMARD data were linked to the National Death Registry and National Patient Register. The latter records all diagnoses given at any hospital admission, inpatient and outpatient, from 2009. CVD was defined as a diagnosis of myocardial infarction, chronic heart failure, cerebrovascular disease or sudden CV death in ICD10. Using cox-regression models, we compared the time until the first recorded CVD diagnosis RA disease remission vs non-remission for the first 4 years after start of therapy. The models were adjusted for age and gender. Additionally, we explored interactions between bDMARD vs. csDMARD, remission and non-remission in age and gender adjusted models.

Results: Data were available for 3251 patients, mean (SD) age, 53.6 (13.5) years, number (\%) females $2483(76.4)$. The total patient years at risk were 5784 , during which there were $65 \mathrm{CVD}$ events. The HR across remission criteria are presented in table 1. Patients in disease remission had a significantly lower HR for CVD compared to those not in remission. There was no statistically significant difference in HR for CVD between patients in remission who were treated with bDMARDs vs csDMARDs.

Table 1.

\begin{tabular}{|c|c|c|c|c|c|c|}
\hline & $\begin{array}{c}\text { NOR-DMARD } \\
\mathrm{N}=3251\end{array}$ & $\mathrm{p}$ & $\begin{array}{l}\text { bDMARDs } \\
\text { N=2622 }\end{array}$ & $\mathrm{p}$ & $\begin{array}{r}\text { csDMARDs } \\
\mathrm{N}=629\end{array}$ & $\mathrm{p}$ \\
\hline & HR $(95 \% \mathrm{Cl})$ & & $\mathrm{HR}(95 \% \mathrm{Cl})$ & & $\mathrm{HR}(95 \% \mathrm{Cl})$ & \\
\hline $\begin{array}{l}\text { DAS28-ESR remis- } \\
\text { sion vs non-remission }\end{array}$ & $0.40(0.21,0.74)$ & 0.01 & $0.30(0.14,0.65$ & 5)0.002 & $\begin{array}{l}0.75 \\
(0.26,2.22)\end{array}$ & \\
\hline $\begin{array}{l}\text { DAS28-CRP remis- } \\
\text { sion vs non-remission }\end{array}$ & $0.48(0.28,0.83)$ & 0.01 & $\begin{array}{l}0.42 \\
(0.23,0.81)\end{array}$ & 0.01 & $0.68(0.2,1.90)$ & 0.46 \\
\hline $\mathrm{CRP}<=10$ & $0.55(0.30,1.03)$ & 0.06 & $0.67(0.31,1.47$ & 7) 0.32 & $0.46(0.16,1.36)$ & \\
\hline Boolean remission & $0.63(0.34,1.84)$ & 0.33 & $0.49(0.15,1.59$ & 0.23 & $0.93(0.21,4.10)$ & \\
\hline DAl rem & $0.70(0.37,1.34)$ & 0.28 & $0.61(0.28,1.34$ & 0.22 & $1.04(0.33,3.30)$ & \\
\hline CDAI remission & $0.69(0.37,1.29)$ & 0.25 & $0.61(0.28,1.34$ & 0.25 & $1.04(0.33,3.30)$ & \\
\hline
\end{tabular}

DAS28-ESR and DAS28-CRP remission: $<2.6$, Boolean remission: tender and swollen joint count $<=1$, CRP $m g / L<=10$, patient global $<1(0-10)$, CDAl remission: $<=2.8$, SDAl remission $<=3.3$
Time to CVD across categories of treatment and remission

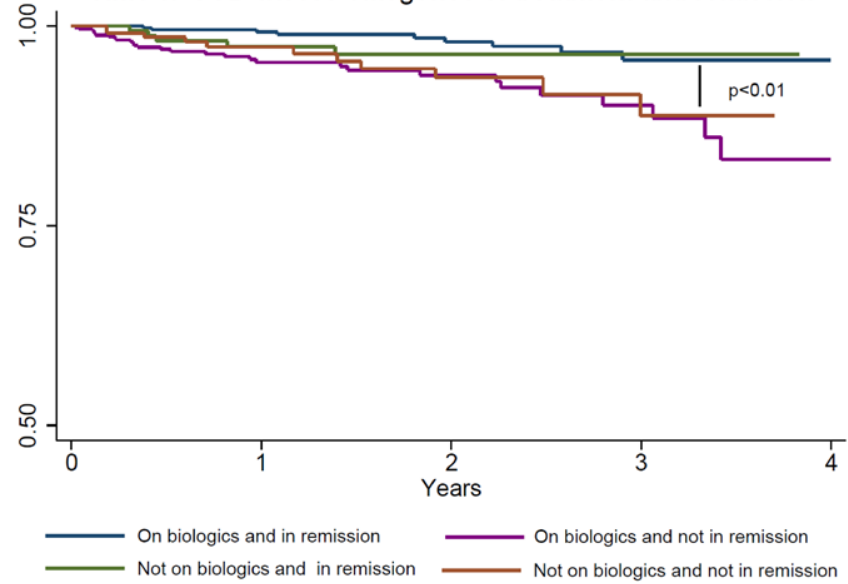

Figure 1

Conclusion: Patients on bDMARDs who achieved DAS28, DAS28-CRP remission, or CRP less than $10 \mathrm{mg} / \mathrm{L}$ by the 6 -month follow-up were less likely to experience a CVD, compared to patients not achieving remission. The HRs for CVD were higher for patients in remission on csDMARDS, compared to patients on bDMARDss, but the difference was not statistically significant and should be further explored.

Disclosure of Interests: Inger Jorid Berg: None declared, Siri Lillegraven: None declared, Eirik kristianslund: None declared, Tore K. Kvien Grant research support from: Received grants from Abbvie, Hospira/Pfizer, MSD and Roche (not relevant for this abstract)., Consultant of: Have received personal fees from Abbvie, Biogen, BMS, Celltrion, Eli Lily, Hospira/Pfizer, MSD, Novartis, Orion Pharma, Roche, Sandoz, UCB, Sanofi and Mylan (not relevant for this abstract)., Paid instructor for: Have received personal fees from Abbvie, Biogen, BMS, Celltrion, Eli Lily, Hospira/Pfizer, MSD, Novartis, Orion Pharma Roche, Sandoz, UCB, Sanofi and Mylan (not relevant for this abstract)., Speakers bureau: Have received personal fees from Abbvie, Biogen, BMS, Celltrion, Eli Lily, Hospira/Pfizer, MSD, Novartis, Orion Pharma, Roche, Sandoz, UCB, Sanofi and Mylan (not relevant for this abstract)., Sella Aarrestad Provan Consultant of: Novartis

DOI: 10.1136/annrheumdis-2020-eular.5773

\section{OP0120 BIOLOGICS MAY PREVENT CARDIOVASCULAR EVENTS IN RHEUMATOID ARTHRITIS BY INHIBITING CORONARY PLAQUE FORMATION AND STABILIZING HIGH-RISK LESIONS}

G. Karpouzas ${ }^{1}$, S. Ormseth ${ }^{2}$, E. Hernandez ${ }^{2}$, M. Budoff ${ }^{1} .{ }^{1}$ Lundquist Institute for Biomedical Innovation, Torrance, United States of America; ${ }^{2}$ Lundquist Institute of Biomedical Innovation, Torrance, United States of America

Background: Biologic disease-modifying antirheumatic drugs (bDMARDs) effectively control inflammation and may improve cardiovascular outcomes in Rheumatoid arthritis.

Objectives: To evaluate if bDMARDs decrease long-term cardiovascular disease (CVD) risk in rheumatoid arthritis and whether potential benefits might be rendered by impacting coronary plaque formation or progression.

Methods: In this single-center observational cohort study, 150 patients underwent computed tomography angiography for evaluation of coronary atherosclerosis (total, non-calcified, mixed/calcified and low-attenuation or high-risk plaque); 101 had repeat assessments within $6.9 \pm 0.3$ years to evaluate plaque progression. All CVD events were prospectively recorded, including cardiac death, myocardial infarction, unstable angina, revascularization, stroke, claudication, and heart failure hospitalization. The Framingham-D'Agostino score assessed clinical risk. Segment stenosis score (cumulative stenosis) measured plaque burden. The effect of bDMARD treatment on CVD events was assessed using marginal structural models. The inverse probability of treatment and censoring weights were used in a weighted pooled logistic regression with current bDMARD use and time since study entry included in the model to approximate a Cox proportional hazards model allowing for time-varying weights. Robust logistic regression evaluated the effect of bDMARD exposure ( $>50$ percent of follow-up period) on likelihood of new plaque formation or change in plaque composition in per-segment models adjusted for Framingham-D'Agostino score, time between scans, statin duration, cumulative prednisone dose and time-averaged CRP. 